\title{
Modalized Questions and Exhaustivity
}

\author{
Benjamin Spector \\ Harvard University
}

\section{Introduction}

Fox and Hackl (2006) noticed the following contrasts:

(1) a. Jack only has to read more than $[\text { three }]_{F}$ books

b. \# Jack is only allowed to read more than [three $]_{\mathrm{F}}$ books

c. \# Jack only read more than $[\text { three }]_{\mathrm{F}}$ books

They show that the acceptability of a sentence of the form $\left[\ldots . . o n l y \ldots . . d_{F} \ldots ..\right]$, where $\mathrm{d}$ is a focused degree-denoting expression, correlates with the availability of a scalar implicature for the very same sentence without only: for instance, Jack has to read more than three books by Balzac generally implicates that Jack does not have to read more than four books by Balzac, while Jack read more than three books by Balzac does not generally implicate that Jack did not read more than four books by Balzac (i.e. does not implicate that Jack read exactly four books). Fox and Hackl (2006) furthermore show that these contrasts (as well as many other facts) follow from the following assumptions:

- The focus value of a degree-denoting expression is the set of all degrees belonging to the same dimension.

- In every dimension, the set of degrees is dense, i.e. given two degrees $\mathrm{d}_{1}$ and $d_{2}$, there is always a degree $d_{3}$ that is strictly 'between' $d_{1}$ and $d_{2}$ relatively to the relevant ordering relation.

- Implicatures are derived by means of a focus-sensitive operator whose semantics is essentially the one proposed for only in Krifka (1993). In case this operator yields the contradictory proposition, no implicature can arise, and inserting only yields an ungrammatical sentence.

I am extremely grateful to Danny Fox. The discussions I had with him contributed a lot to this paper. I also thank Jeroen Groenendijk and an anonymous reviewer for an interesting suggestion that I could not fully take into account in this paper. Many thanks also to Ivona Kucerova for sharing with me relevant data from Czech. I benefited from various comments from the audience of the MIT question reading group (Fall 2006), and the 'Journées Sémantique et Modélisation' (March 2007, Paris). I gratefully acknowledge the support of the Ecole Normale Supérieure in Paris ( $\mathrm{D}^{\mathrm{pt}} \mathrm{d}$ 'Etudes Cognitives, of which I am an associate member) and of the MIT-France Seed Fund Grant for Collaborative Research on Presuppositions and Implicatures (2006-2007). 
In this paper, I am not going to challenge Fox and Hackl's account. Rather I will show that modified numerals follow exactly the pattern they have identified even when the focused element is not the numeral itself, but the entire DP that contains the numeral. In this case the nature of "measurement scales" is simply irrelevant, and a separate account is anyway called for. Thus consider the following question-answer pairs:

(2) a. What books does Jack have to read in order to pass the exam?

b. Jack has to read [more than three novels by Balzac $]_{F}$

(3) a. What books is Jack allowed to read ?

b. Jack is allowed to read [more than three novels by Balzac $]_{\mathrm{F}}$

(4) a. What books did Jack read ?

b. Jack read [more than three novels by Balzac $]_{F}$

While (2b) implicates that Jack does not have to read more than four novels by Balzac (and, in fact, that he has no reading obligation apart from reading more than three novels by Balzac), no similar inference is available for (3b) and (4b). In other words, Fox and Hackl's (2006) facts are entirely preserved in all these cases. But their account cannot be easily extended, because the alternatives (i.e. the focus values) of (2b), (3b), and (4b) include more than just what would result from replacing the numeral with an other numeral. The focus value of an increasing generalized quantifier, indeed, is usually assumed to be the set of all (relevant) increasing generalized quantifiers (in fact, this is clearly needed if one wants to account for the fact that $2 b$, for instance, also implicates that Jack does not have to read, say, any novels by Flaubert). To put things differently, the set of propositions denoted by the underlying question (2a) (respectively, $3 \mathrm{a}$ and $4 \mathrm{a}$ ), includes more than just those that can be expressed by sentences of the form [Jack has to <resp. is allowed to, $\varnothing$ read more than $n$ books by Balzac] - this set is in fact the denotation of a how many-question.

In this paper, I will offer an account of these contrasts (together with other facts) based on the following intuitions:

- The pragmatic meaning of a sentence $\mathrm{S}$ with alternatives $\operatorname{Alt}(\mathrm{S})$ is the exhaustive interpretation of $\mathrm{S}$ when given as an answer to a question whose denotation is $\operatorname{Alt}(\mathrm{S})$.

- Interpreting an answer as exhaustive means the same as assuming that the answer IS the complete answer to the question.

- (2b) is, in some contexts, the actual complete answer to (2a): namely, (2b) is the actual complete answer in any world in which Jack has to read more than three novels by Balzac and has no other reading obligation. On the other hand, (3b) cannot be the complete answer to (3a), and (4b) cannot be the complete answer to (4a). 
I will first show that the interpretation of wh-questions containing a modal operator motivates a revision of standard assumptions. Then I will offer a theory of exhaustive interpretations. These two separate proposals, when combined, will be able to account for the above contrasts. It will turn out that the whole account is entirely consistent with the general perspective outlined by Fox (2007b).

\section{An Unnoticed Reading for Wh-Questions: Wh-Phrases as Higher-Order Quantifiers}

Consider the following question:

Which books does Jack have to read?

According to Karttunen's (1977) - henceforth K.- semantics for questions, the complete answer to (5), in a given world $\mathrm{w}$, is the proposition expressed by the conjunction of all the statements of the form 'Jack must read $\mathrm{x}$ ', with $\mathrm{x}$ a book, that are true in w, if there are such true statements; if, in w, there is no book $\mathrm{x}$ such that Jack must read $\mathrm{x}$, then the complete answer is the proposition that states that there are no particular books that Jack must read. According to Groenendijk \& Stockhof's (1984) - henceforth G\&S- partition semantics, the complete answer to (5) is the proposition that states what the extension of the predicate $2 x .(x$ is a book and Jack has to read $x)$ is in $\mathrm{w}^{1}$. Consider now the following situation: there are books on a table, call them A, B, C, etc. Jack's actual reading obligations are as follows: he has to either read $\mathrm{A}$ and $\mathrm{B}$, or $\mathrm{C}$ and $\mathrm{D}$, and he has no other reading obligations. It follows that there is no particular book x such that Jack must read x. As a result, both $\mathrm{K}$. and G\&S. predict that the complete answer in this case is the proposition expressed by there are no books that Jack must read. Yet it seems that a cooperative speaker who knows what Jack's reading obligations are is likely to provide the answerer with the information that Jack must either read $\mathrm{A}$ and $\mathrm{B}$, or $\mathrm{C}$ and $\mathrm{D}$. But this proposition is not even predicted to be a partial answer by $\mathrm{K}$. and G\&S, as its truth has no implication whatsoever regarding the extension of $\lambda x$. ( $x$ is a book \& Jack has to read $x$ ). This observation suggests that the semantics of wh-questions should be amended, so that the proposition that Jack has to either read A and B or C and D counts as the complete answer in such a situation.

For sure, one could claim that our observation actually boils down to the fact that speakers, when answering a question, often choose to address another question which they believe the questioner is interested in; in the above case, the

\footnotetext{
${ }^{1}$ In both systems, as well as in subsequent works, which-phrases are treated as binding an etype variable, unless we are dealing with pair-list or functional readings (Engdahl 1986, Chierchia 1991, Sharvit 1999).
} 
answerer may assume that the questioner is interested in whatever reading obligation Jack has, and choose to give an answer to What are Jack's reading obligations? In the next sub-sections, I'll give several arguments that such a pragmatic account is not sufficient. These arguments are based on the interpretation of embedded wh-questions and of elided answers to wh-questions.

\subsection{Embedded Modalized Wh-Questions}

Consider the following scenario: Jack must read books A and B and he also has to read a third book, which can be either book $\mathrm{C}$ or book $\mathrm{D}$; he has no other reading obligation. In other words, his reading obligations are exactly as follows: read A and $\mathrm{B}$ and $(\mathrm{C}$ or $\mathrm{D})$. Mary knows that Jack must read A and B, and that there is no other particular book that Jack must read, but she does not know that Jack has to either read $\mathrm{C}$ or D. In such a situation, Mary knows what the extension of $\lambda \mathrm{x}$. ( $x$ is a book that Jack has to read) is. Hence, according to both K. and G \& S, she happens to be in the relation denoted by know to the complete answer to Which books does Jack have to read? Following Karttunen (1977), G \& S (1984), Heim (1994), Lahiri (2002), let us assume that a sentence of the form Mary knows $Q$, where $\mathrm{Q}$ is an interrogative clause, is true in a world $\mathrm{w}$ if and only if Mary is, in $\mathrm{w}$, in the relation denoted by know to the proposition that is the complete answer to $\mathrm{Q}$ in $\mathrm{w}$. Then, in this scenario, the following sentence is predicted to be true ${ }^{2}$ :

Mary knows which books Jack has to read

Yet there is clearly a reading under which (6) is false in the above scenario $^{3}$. Indeed, one could easily object to (6) as follows:

No! Mary does not know that Jack has to read book C or book D.

This shows that there is a reading under which (6), in such a situation, entails that Mary knows that Jack must read A and B, and that he must read C or D. If we maintain the standard view that Mary knows $Q$ is true iff Mary is in the relation denoted by know to the actual complete answer to $\mathrm{Q}$, then the complete answer to Which books does Jack have to read? has to entail, in the above scenario, Jack has to read books $A$ and $B$ and either book $C$ or book D. This requires a revision of the semantics of wh-questions ${ }^{4}$.

\footnotetext{
${ }^{2}$ Both under the 'strongly exhaustive' reading and the 'weakly exhaustive' reading.

${ }^{3}$ There is also a reading of (6) under which (6) is true, though this reading is not the most natural one. Thus it is possible to give the following reply to (7): "What I meant is that Mary knows which particular books Jack definitely has to read".

${ }^{4} \mathrm{Of}$ course, one can question K's and G \& S's assumption regarding the interpretation of embedded questions, and argue that $X$ knows $Q$ (with Q a question) is true if $\mathrm{X}$ knows the truth of
} 
Here is an informal presentation of such a possible revision. Let us assume that wh-questions are systematically ambiguous between two types of reading, which, in the case of (5), can be paraphrased as follows:

(8) a. For which books $\mathrm{x}$, is it the case that Jack has to read $\mathrm{x}$ ?

b. For which generalized quantifier $\mathrm{G}$ over books, Jack has to read $\mathrm{G}^{5}$ ?

On the b-reading, the complete answer to (5) is the strongest true proposition of the form Jack has to read $G$, with $\mathrm{G}$ a generalized quantifier over books. In the above scenario, the complete answer so defined is the proposition expressed by Jack has to read books $A$ and $B$ and either book $C$ or book D. From now on, I will call this reading the higher-order reading of wh-questions. The other reading, paraphrased in (8a), I call the individual reading of wh-questions.

\subsection{Elided Quantified Answers and Weak Island Effects}

Consider the following question-answer pairs:

(9) a. Which books must we read?

b. The French novels or the Russian novels

(10) a. Which books did Jack demand that we read?

b. The French novels or the Russian novels

(11) a. Which books did you expect Mary to read?

b. The French novels or the Russian novels

In each of the above examples, the elided answer can be interpreted either in the position of the wh-gap, or as taking wide scope. That is, (9b), (10b) and (11b) give rise to the following ambiguities, respectively:

(12) a. We must either read the French novels or the Russian ones - it's up to us which ones

b. Either we must read the French novels, or we must read the Russian ones novels (I don't remember which)

(13) a. Jack demanded that we either read the French novels or the Russian ones - it's up to us which ones

b. Either Jack demanded that we read the French novels, or he demanded that we read the Russian ones (I don't know)

a proposition $\mathrm{S}$ that is a maximally relevant answer to Q in a broad sense. See Ginzburg (1995a, 1995b), and van Rooij (2003) for proposals along this line.

${ }^{5} \mathrm{~A}$ generalized quantifier $\mathrm{G}$ is said to be (or range) 'over $\mathrm{P}$ ', where $\mathrm{P}$ is a set of individuals, iff $P$ is the smallest live-on set of G (see Szabolcsi 1997). The smallest live-on set of a GQ G is the smallest set A such that : $\forall \mathrm{Y}(\mathrm{Y} \in \mathrm{G} \Leftrightarrow(\mathrm{Y} \cap \mathrm{A}) \in \mathrm{G})$.

Fact: For any conservative Det, the smallest live-on set of $\llbracket$ Det NP】is $\mathbb{N P} \rrbracket$ 
(14) a. I expect Mary to either read the French novels or the Russian ones

b. Either I expect Mary to read the French novels, or I expect her to read the Russian ones <odd: suggests that I don't know what I expect>

It turns out that the narrow-scope reading is subject to interesting grammatical constraints. In all of the following examples, the answer is not ambiguous, and can only receive a wide-scope interpretation:

a. Which books didn't Jack read?

b. The French novels or the Russian novels

$\rightarrow$ Unavailable reading: it is not the case that Jack either read the French novels or the Russian novels $=$ Jack read neither the Russian nor the French novels

$\rightarrow$ Available reading: Jack didn't read the French novels, or he didn't read the Russian novels

(16) a. ? Which books did Mary ask whether Jack read?

b. The French novels or the Russian novels

$\rightarrow$ Unavailable: Mary asked whether Jack either read the French novels or the Russian novels

$\rightarrow$ Available: Either Mary asked whether Jack read the French novels, or she asked whether he read the Russian ones

(17) a. Which books did Mary discover that Jack read ?

b. The French novels or the Russian novels

$\rightarrow$ Unavailable: Mary discovered that Jack either read the French novels or the Russian novels (could be true in a situation in which Jack read the French novels but not the Russian ones and Mary discovered that Jack read either the French novels or the Russian ones without knowing that he in fact read the French ones)

$\rightarrow$ Available: Either Mary discovered that Jack read the French novels, or she discovered that he read the Russian ones (presupposes that Jack actually read both the French novels and the Russian novels)

It appears that negation, embedded interrogatives and factive verbs block the 'narrow-scope' reading of elided answers. This typology is familiar: namely, the narrow-scope reading of elided answers is blocked in weak-islands environment. Why could this be so? It is natural to assume that the 'narrowscope' reading of elided answers arises when the underlying question is itself interpreted under its 'higher-order' reading. Note indeed that under the 'individual' reading, the narrow-scope reading of an elided answer would not 
even count as a partial answer ${ }^{6}$. Hence we are led to assume that the higher-order reading of wh-questions is itself subject to weak-islands, which would explain why the narrow-scope reading of elided answers in unavailable in weak-island environments ${ }^{7}$. If this is so, embedded wh-questions that contain a weak-island are expected not to license the higher-order reading, a prediction that we now put to test in the case of factive islands. Consider the following dialogues:

a. Sue knows which books Mary demanded that Jack read

b. No! Sue knows that Mary demanded that Jack read the Italian novels, but she does not know that Mary furthermore demanded that Jack either read the French novels or the Russian novels (though she did not have more precise demands)

(19) a. Sue knows which books Mary discovered that Jack read

b. \# No! Sue knows that Mary discovered that Jack read the Italian novels, but she does not know that Mary furthermore discovered that Jack either read the French novels or the Russian novels (though she does not know which ones)

The naturalness of (18b) is predicted only if the higher-order reading is licensed for which books Mary demanded that Jack read: indeed, the fact that Sue does not know that Mary demanded that Jack read the French novels or the Russian novels does not entail that Sue does not know the extension of $\lambda x$. ( $x$ is a book that Mary demanded that Jack read), hence does not justify an objection to (18a) if which books Mary demanded that Jack read is interpreted under its 'individual' reading. On the other hand, the truth of (18b) entails that Sue does not know the truth of the most informative true sentence of the form Mary demanded that Jack read G, with G a GQ over books, i.e. does not know the complete answer to which books Mary demanded that Jack read under the higherorder interpretation. By a parallel reasoning, the infelicity of (19b) leads us to conclude that the higher-order reading is unavailable for which books Mary discovered that Jack read: if such a reading were available, then (19b) should count as a felicitous reply, given that it indeed entails that Sue is not in the relation know to the strongest true proposition of the form Mary discovered that

\footnotetext{
${ }^{6}$ Except in some particular cases, such as (15a): any answer of the form Jack didn't read G, with G a GQ over books, can be reformulated as a boolean combination of sentences of the form Jack didn't read $x$, with $\mathrm{x}$ being an individual book.

${ }^{7}$ In my SALT talk, I showed that the higher-order reading is sensitive to weak-islands in a way that is fully parallel to the pattern discovered by Fox and Hackl (2006) for degree questions: namely, negative islands can be obviated if negation scopes over a possibility modal. Thus, in the following question-answer pair, the answer can be interpreted as taking scope below allowed: - What books are we not allowed to read ? The Russian novels or the French novels

Possible interpretation: 'We are neither allowed to read the Russian novels nor the French ones'
} 
Jack read $G$, with $\mathrm{G}$ a GQ over books. It therefore appears that the higher-order reading of embedded wh-questions is subject to factive islands.

The fact that this "higher-order" reading is sensitive to such grammatical constraints strongly suggests that it corresponds to a genuinely distinct reading of wh-questions (and is not simply a pragmatic effect).

\subsection{Proposal}

If these arguments are conclusive, we need to posit that questions such as (5) are truly ambiguous between two readings. As suggested above, these two readings can be informally paraphrased as follows:

(20) a. For which books $\mathrm{x}$, is it the case that Jack must read $\mathrm{x}$ ?

b. For which generalized quantifier $G$ over books, Jack must read G?

In fact, it is necessary to impose an additional restriction on the variable G. G should range over increasing GQs over books. The motivation for this restriction is the following. Suppose that Jack has to read at least two novels by Balzac, and is furthermore not allowed to read any novel by Nabokov, and that these are his only obligations. Then the strongest true statement of the form Jack has to read G, with G a GQ over books, is Jack must read at least two novels by Balzac and no novel by Nabokov. In the absence of any particular restriction, it is thus predicted that the sentence Sue knows what books Jack must read is true in this situation only if Sue knows that Jack must read at least two novels by Balzac and no novel by Nabokov. However, it seems that the sentence in question is true as soon as Sue knows that Jack must read at least two novels by Balzac. This fact is readily explained if we replace (20b) with the following:

(21) For which increasing generalized quantifier $\mathrm{G}$ over books, is it the case that Jack must read G?

Let me offer a more formal rendering of this proposal. One possible implementation is to treat wh-phrases as ambiguous, as shown below (as in K. the denotation of a question is taken to be a set of propositions) ${ }^{8}$ :

\footnotetext{
${ }^{8}$ Two remarks are in order: i) Instead of locating the ambiguity in the wh-phrase itself, it is certainly possible to treat it as a syntactic ambiguity. The "higher-order" reading could plausibly be derived by syntactic reconstruction. If this were so, we would expect certain correlations between condition $\mathrm{C}$ of Binding Theory and the presence or absence of the higher-order reading (see Fox 1999 for examples involving a similar ambiguity in how-many questions). Kucerova (2007) provides preliminary evidence from Czech for a syntactic account of the ambiguity: Czech split wh-questions, which are constrained by weak-islands, can only be interpreted under the higher-order reading. ii) (22) might need to be modified so that the variable G, instead of ranging over generalized quantifiers, ranges over intensional counterparts of generalized quantifiers (i.e. functions from worlds to GQs, type $<\mathrm{s},<<\mathrm{e}, \mathrm{t}>, \mathrm{t}>>)$ ). Such a modification would be hard to
} 
a. $\llbracket(\text { What NP })_{\mathrm{i}} \mathrm{S} \rrbracket(\mathrm{w})=\lambda \varphi_{<\mathrm{s}, \mathrm{t}>} . \varphi(\mathrm{w})=1 \& \exists \mathrm{x}_{<\mathrm{e}>}\left(\mathrm{x} \in \llbracket \mathrm{NP} \rrbracket \& \llbracket \mathrm{S} \rrbracket^{\mathrm{i} \rightarrow \mathrm{x}}=\varphi\right)$

b. $\quad\left[(\text { What NP })_{\mathrm{G}} \mathrm{S} \rrbracket(\mathrm{w})=\lambda \varphi<\mathrm{s}, \triangleright . \varphi(\mathrm{w})=1 \& \exists \mathrm{X}_{<<\mathrm{e}, \triangleright, \downarrow, \downarrow}(\mathrm{X}\right.$ is increasing and its smallest live-on set belongs to $\llbracket \mathrm{NP} \rrbracket \& \llbracket \mathrm{S} \rrbracket^{\mathrm{G} \rightarrow \mathrm{X}}=\varphi$ )

(22a) is basically identical to K.'s proposal: the denotation of Which books must Jack read? is, given (22a), the set of all the true propositions of the form 'Jack must read x', with $\mathrm{x}$ standing for a (possibly plural) individual made up of books. According to (22b), the denotation of the very same question is the set of all the true propositions of the form 'Jack must read G', with $G$ an increasing GQ ranging over books. Our observations regarding the weak-island sensitivity of the low-reading are then reducible to the claim that wh-phrases of the type of (22b) cannot be moved across weak islands - I do not provide an account of this fact.

I now turn to the analysis of exhaustive interpretation. The next section is, as such, entirely independent of the second one.

\section{A Simple Theory of Exhaustive Interpretations}

\subsection{Exhaustive Interpretations: Assuming That an Answer Is Complete}

For any given question Q and world w, I define the complete answer to Q in w as the logically strongest member of the denotation of Q. Let Q be Which books did you read? and $\mathrm{w}$ be such that I read books A and B and no other book in w. Under its individual reading, $\mathrm{Q}$ denotes in $\mathrm{w}$ the set of all propositions of the form I read $x$, with $\mathrm{x}$ a book or a plurality of books that I read in $\mathrm{w}^{9}$.

So we have: $\mathrm{Q}_{\text {individual-reading }}(\mathrm{w})=\{$ the proposition that $\mathrm{I}$ read $\mathrm{A}$, the proposition that $\mathrm{I}$ read $\mathrm{B}$, the proposition that $\mathrm{I}$ read $\mathrm{A}$ and $\mathrm{B}$ \}. Hence the complete answer in this case is the proposition that I read A and B, as Karttunen would have had it ${ }^{10}$.

On the higher-order reading, the denotation of $\mathrm{Q}$ in $\mathrm{w}$ is the following set: Qhigher-order reading $(\mathrm{w})=$ \{that I read A, that I read B, that I read A or B, that I read A and $\mathrm{B}$ \}. Hence the complete answer in this case is the same as before, namely, the

distinguish, I believe, from an alternative proposal that was suggested to me by Jeroen Groenendijk and an anonymous reviewer: the higher-order reading would not involve quantification over GQs, but quantification over properties (i.e. functions from worlds to sets of individuals). According to this alternative account, the right paraphrase for the higher-order reading would be "For what property $\mathrm{P}$, is it true that Jack has to read an individual X made up of novels and having property P". Such a property could be, for instance, that of being the books A and $\mathrm{B}$ or the books $\mathrm{C}$ and D. I intend to investigate this alternative analysis in future work.

${ }^{9}$ In the whole paper, it is assumed that the domain of individuals is a joint semi-lattice structured by a part-whole relation, consisting of both of atomic individuals (the minimal members of the domain, which have no proper part) and of plural individuals (also called 'pluralities') made up of atomic individuals, as is standard in many works concerned with the semantics of plural expressions. 
proposition that I read A and B. Basically, in all the cases that I am going to consider in this question, the individual-reading and the higher-order reading give rise to the same notion of complete answer - this will be so as long as no operator intervenes between the wh-phrase and the gap.

Consider now the following dialogue:
a. Which novels did Mary read?
b. Mary read Ulysses and Madame Bovary

Suppose that, by default, it is assumed that the answer given to a question is the actual complete answer to the question. Then (23b) will be interpreted as: 'That Mary read Ulysses and Madame Bovary is the complete answer to Which novels did Mary read?". This is in fact equivalent to: "Mary read Ulysses and Madame Bovary and did not read any other novel". So here is a mechanism that generates the exhaustive interpretation in simple cases. This procedure actually mirrors Krifka's (1993) semantics for only, according to which only $S$ asserts that $\mathrm{S}$ is the logically strongest true proposition within its alternatives. Let us introduce an operator $O p_{Q}$ which, when applied to a proposition $\mathrm{S}$, returns the proposition that states that $\mathrm{S}$ is the complete answer to $\mathrm{Q}$ :
a. $\llbracket \mathrm{Op}_{\mathrm{Q}} \mathrm{S} \rrbracket(\mathrm{w})=1$ if $\mathrm{S}$ is the strongest member of $\mathrm{Q}(\mathrm{w})$
b. $\llbracket \mathrm{Op}_{\mathrm{Q}} \rrbracket=\lambda \phi . \lambda \mathrm{w} .(\phi \in \mathrm{Q}(\mathrm{w}) \wedge \forall \psi((\psi \in \mathrm{Q}(\mathrm{w})) \rightarrow(\phi \subseteq \psi)))$

\subsection{The Limitations of $O p_{Q}$}

As has been noticed by van Rooij \& Schulz (2006) among others (and anticipated by Groenendijk \& Stockhof 1984), $O p$ fails to give rise to the right result as soon as it applies to a disjunctive or indefinite answer. Let me illustrate this fact in the case of a disjunctive answer:

(25) a. Which novels did Mary read?

b. Mary read Ulysses or Madame Bovary

Applied to (25b), $O p_{(25 a)}$ returns the following proposition:

(26) The proposition that Mary read Ulysses or Madame Bovary is the complete answer to Which novels did Mary read?

It turns out that (26) is contradictory. Indeed, any world w has one of the following properties: a) Mary read neither Ulysses nor Madame Bovary in w, b)

\footnotetext{
${ }^{10}$ It is in principle possible that denotation of a question $\mathrm{Q}$ in $\mathrm{w}$ is such that none of its members entails all the others, in which case there is no complete answer to $\mathrm{Q}$ in $\mathrm{w}$.
} 
Mary read Ulysses but did not read Madame Bovary in w, c) Mary read Madame Bovary but did not read Ulysses in w, and d) Mary read both Ulysses and Madame Bovary in w. In the a) case, (25b) is false and therefore cannot be the complete answer, so (26) is false. In the b) case, the complete answer to (25a) is the proposition that states that Mary read Ulysses, hence (25b) is true but is not the complete answer, and therefore (26) is false. By symmetry, (26) is false also in the c) case. And in the d) case, the complete answer to (25a) is the proposition that Mary read both novels, so (25b) is true but is not the complete answer, and therefore (26) is false.

So a theory of exhaustivity based on $O p_{Q}$ predicts that the exhaustive interpretation of a disjunctive answer is the contradictory proposition; this amounts to saying that a disjunctive answer does not undergo any kind of strengthening (since no sensible speaker would assume that the intended meaning of an answer is the contradictory proposition, it will simply be assumed that $O p_{Q}$ is absent). This of course conflicts with well-known observations: namely, an answer such as (25b) tends to be interpreted as conveying that Mary read only one of the two novels Ulysses and Madame Bovary and did not read any other novel.

In order to solve this problem, van Rooij \& Schulz $(2004,2006)^{11}$ defends (and improves on) the original proposal of Gronendijk \& Stockhof (1984), and define an exhaustivity operator which, when applied to a disjunctive answer, yields the desired result. In the rest of this section, I am going to follow a different route: namely, I'll show that a theory of exhaustivity based on $O p_{Q}$ can be maintained provided we allow $O p_{Q}$ to be inserted under the scope of some operators instead of being forced to apply to the answer as a whole. It will be shown that such a theory is able to predict that modified numerals and bare numerals give rise to different implicatures in simple contexts ${ }^{12}$.

\subsection{A Syntactic Trick ${ }^{13}$}

Let us go back to the problematic case that involved a disjunction:
a. Which novels did Mary read?
b. Mary read [Ulysses or Madame Bovary $]_{\mathrm{f}}$

Let us now assume that (27) can be interpreted as corresponding to the following logical form:

\footnotetext{
${ }^{11}$ See also Spector $(2003,2006)$

${ }^{12}$ That is, (A) Jack read more than two novels does not implicate that Jack read exactly three novels, as oppposed to (B) Jack read three novels. Yet we take A and B to express the same proposition. But see fn. 15 .

${ }^{13}$ The proposal presented in this section has been independently suggested by Ezra Keshet (2006). I first developed it in my dissertation (Spector 2006: appendix 2, chapter 2: 214-236). Keshet credits Kratzer (2005) for a similar idea.
} 
Now what is the denotation of $\lambda x .\left(O p_{(27 a)}\right.$ (Mary read $\left.\left.x\right)\right)$ ? Recall that $O p_{(27 a)}$ (Mary read $x$ ) stands for "the proposition that Mary read $\mathrm{x}$ is the complete answer to Which novels did Mary read?". Therefore $\lambda x$.(Op $(27 a)$ (Mary read x))) denotes the set of individuals $\mathrm{d}$ such that the proposition that Mary read $\mathrm{d}$ is the complete answer to Which novels did Mary read? In other words, it is the set of individuals $d$ such that $d$ is the maximal plurality of novels read by Mary. This set is a singleton set whose only member is the plural entity made up of all the novels that Mary read:

$$
\llbracket \lambda x .\left(\mathrm{Op}_{(27)}(\text { Mary read } \mathrm{x})\right) \rrbracket(\mathrm{w})=\lambda \mathrm{x} .(\mathrm{x}=\text { the novels that Mary read in } \mathrm{w})
$$

Following a standard treatment of disjunction, 'Ulysses or Madame Bovary' denotes the following generalized quantifier:

$$
\begin{aligned}
& \llbracket \text { Ulysses or Madame Bovary } \rrbracket=\lambda \mathrm{P}_{<\mathrm{e}, \triangleright} \cdot\left(\mathrm{P}(\text { Ulysses })=1 \text { or } \text { incl }_{1} \mathrm{P}(\text { Madame }\right. \\
& \text { Bovary })=1)
\end{aligned}
$$

So in general an expression of the form 'Ulysses or Madame Bovary $\mathrm{P}$ ' is true if and only if one of the two novels has the property denoted by $\mathrm{P}$, including the case where both novels have this property. But it is a logical fact that two distinct individuals $\mathrm{A}$ and $\mathrm{B}$ cannot both have the property denoted by $\lambda x$. ( $x=$ the novels that Mary read), since this property always denote the singleton set whose only member is the individual made up of all the novels that Mary read. Since (28) says that the property of being all the novels that Mary read applies to Ulysses or to Madame Bovary, it means that Mary read either Ulysses and no other novel, or Madame Bovary and no other novel. So by allowing $O p$ to be inserted under the scope of the disjunctive phrase, one can in fact derive the desired reading. A theory of scalar implicatures and exhaustive readings based on $O p_{Q}$ can therefore be entertained, provided it includes the option of inserting $O p_{Q}$ under the scope of some other expressions ${ }^{14}$. The next sections show that such a theory is able to account for the interpretation of bare and modified numerals in various contexts.

\subsection{Bare and Modified Numerals}

The following two sentences, when used as answers to Which novels did Jack read?, give rise to different implicatures:

\footnotetext{
${ }^{14}$ As discussed in my SALT hand-out, such a theory needs to be supplemented with a constraint that prevents the 'syntactic trick' presented in this section from being used in the case of negative answers, i.e. answers that use a monotone-decreasing quantifier. Without such a restriction, clearly unattested readings would be generated for negative answers.
} 
(31) Jack read more than two novels by Balzac

(32) Jack read three novels by Balzac

While (32) implicates that Jack read exactly three novels by Balzac (and no other novel), (31) suggests that the speaker does not know the exact number of novels by Balzac that Jack read (and that he read only novels by Balzac). Yet these two sentences, before pragmatic strengthening, have the same truthconditions: both are true if and only if Jack read at least three novels by Balzac ${ }^{15}$. It follows 16 that an exhaustivity operator that applies globally to answers cannot derive different implicatures for (31) and (32). In particular, applying $O p_{Q}$ globally to (31) and (32) yields, in both cases, the contradictory proposition:

Op $\mathrm{p}_{\mathrm{Q}}$ (Jack read more than two novels by Balzac)

$\mathrm{Op}_{\mathrm{Q}}(\mathrm{Jack}$ read three novels by Balzac)

These two logical forms are respectively equivalent to:

(35) The complete answer to Which novels did Jack read? is 'Jack read more than two novels by Balzac'

(36) The complete answer to Which novels did Jack read? is 'Jack read three novels by Balzac'

Both (35) and (36) are plain contradictions: the complete answer to Which novels did Jack read? is the proposition expressed by Jack read X, where $\mathrm{X}$ denotes the individual made up of all the novels that Jack read ${ }^{17}$. Since neither (35) nor (36) is equivalent to a sentence of this form, there is no world in which they count as the complete answer to Q. Assuming that $O p_{Q}$ can be inserted within the scope of the quantifier, the only non-contradictory way to strengthen the meaning of (31) and (32) is to interpret them according to the following logical forms:

[More than two novels by Balzac] $[\lambda x$. Op $\mathrm{Q}(\mathrm{Jack}$ read $\mathrm{x})]$ [Three novels by Balzac] $\left[\lambda x . \mathrm{Op}_{\mathrm{Q}}(\operatorname{Jack}\right.$ read $\left.\mathrm{x})\right]$

\footnotetext{
${ }^{15}$ I am ignoring the possibility, defended by various authors, that bare numerals are ambiguous, between an exactly $n$ reading and an at least $n$ reading. I assume that the exactly $n$ reading is the result of pragmatic strengthening.

${ }^{16}$ Unless (31) and (32) are assumed to have distinct alternatives, as in Spector (2006) and Russell (2006). van Rooij \& Schulz (2006) note that even though (31) and (32) have the same truth-conditions, they are not equivalent if a richer notion of meaning is adopted, as in Dynamic Semantics. In DRT, for instance, (31) introduces a discourse referent associated with the condition 'being of cardinality greater than two', while (32) introduces a discourse referent associated with the condition 'being of cardinality exactly three'. van Rooij \& Schulz's exhaustivity operator is sensitive to this difference and derives the 'exactly three'-reading only for (32).

${ }^{17}$ As explained above, this is so both under the individual and the higher-order reading.
} 
I assume the following denotations for more than two and three:

$$
\begin{aligned}
& \llbracket \text { More than two } \rrbracket=\lambda \mathrm{P}_{<\mathrm{e}, \mathrm{t}} . \lambda \mathrm{Q} . \exists \mathrm{X}(\# \mathrm{X}>2 \quad \& \mathrm{P}(\mathrm{X})=1 \& \mathrm{Q}(\mathrm{X})=1) \\
& \llbracket \text { Three } \rrbracket=\lambda \mathrm{P}_{<\mathrm{e}, \mathrm{t}>} . \lambda \mathrm{Q} . \exists \mathrm{X}(\# \mathrm{X}=3 \quad \& \mathrm{P}(\mathrm{X})=1 \& \mathrm{Q}(\mathrm{X})=1)
\end{aligned}
$$

Even though more than two and three have different denotations, sentences of the form more than two As $B$ and three As $B$ are nevertheless equivalent as long as $\mathrm{A}$ and $\mathrm{B}$ are distributive predicates ${ }^{18}$. But this is not so if $\mathrm{B}$, say, is not a distributive predicate. The predicate $\lambda x . O p_{Q}($ Jack read $x)$ is precisely not a distributive predicate, since it can be adequately paraphrased by being all the novels read by Jack. If $\mathrm{X}$ has the property of being all the novels read by Jack, then no proper subpart of X can have this property. So (37) and (38) are not expected to be equivalent. Let us compute their truth-conditions:

- (37) is true if and only if there is a plurality X of novels by Balzac whose cardinality is more than two and such that they are all the novels read by Jack. This is equivalent to 'Jack read more than two novels by Balzac and did not read any other novel', which is the desired result.

- (38) is true if there is a plurality X of novels by Balzac whose cardinality is exactly three and such that they are all the novels read by Jack. This is equivalent to 'Jack read exactly three novels by Balzac and did not read any other novel'. This is again the desired result.

\section{Modified Numerals in Modal Contexts}

\subsection{Modified Numerals under a Necessity Modal}

We are now in a position to derive the contrast that was our starting point. We have just shown that the theory of exhaustivity presented in the previous section predicts that a focused DP of the form more than $n$ NPs does not yield an exactly $n+1$ reading when it is not embedded under any operator. We now have to show that a sentence of the form Necessary [...[more than $n N P s]_{f} .$. ] is predicted to implicate Not [Necessary [...[more than $n+1$ NPs]...]. The results of section 2

\footnotetext{
${ }^{18}$ That Three Ps $Q$ entails More than two Ps $Q$ is trivial (and true even when $\mathrm{P}$ or $\mathrm{Q}$ is not distributive). In the other direction, suppose that more than two $P S Q$ is true. Then there is a plurality $X$ made up of more than two atomic individuals such that $P(X)=1$ and $Q(X)=1$. Let $X^{\prime}$ be a part of $X$ such that $X^{\prime}$ is of cardinality exactly 3. Since $P$ and $Q$ are assumed to be distributive predicates (i.e. if they are true of an individual I, they are true of any part of I), $X^{\prime}$ is a plurality consisting of exactly three atomic individuals such that $P\left(X^{\prime}\right)=1$ and $Q\left(X^{\prime}\right)=1$. Therefore there exists a plurality $\mathrm{Y}$ such that $\mathrm{Y}$ is of cardinality exactly three and $\mathrm{P}(\mathrm{Y})=1$ and $\mathrm{Q}(\mathrm{Y})=1$ (namely, take $\mathrm{Y}=\mathrm{X})$. Hence Three Ps $Q$ is true.
} 
will now become relevant. Let us return to the question-answer pair given in (2), repeated below as $(41)$ :

(41) a. What books does Jack have to read in order to pass the exam?

b. Jack has to read [more than three novels by Balzac $]_{\mathrm{F}}$ in order to pass the exam

The crucial point here is that (41b) CAN actually be the complete answer to (41a) if (41a) is understood under its higher-order reading. On this reading, (41a) denotes, in a given world, the set of all true propositions of the form Jack has to read $G$, with $\mathrm{G}$ an increasing GQ over novels. Now, in a situation in which Jack's only reading obligation is to read more than three novels by Balzac, the strongest such proposition is precisely expressed by Jack has to read more than three novels by Balzac. Therefore applying the operator $O p_{Q}$ to (41)b as a whole does not result in a contradiction; rather, it yields the proposition expressed in (42a), which is equivalent to (42b).

(42) a. 'Jack has to read more than three novels by Balzac' is the strongest true sentence of the form 'Jack has to read G', with G an increasing GQ over novels

b. Jack has to read more than three novels by Balzac and he has no other reading obligation as far as novels are concerned

Now, one of the consequences of (42) is that Jack does not have to read more than four novels by Balzac, which is what we wanted to account for. Note that (42) says more than that; namely, it also asserts that Jack is free to choose which novels by Balzac he should read, i.e. there is no definite book by Balzac that he has the obligation to read; it also entails that Jack does not have to read any novel that is not by Balzac. This 'freedom of choice' effect is actually not predicted by Fox and Hackl's (2006) treatment of the very same sentence when given as an answer to a how-many question. Combined together, my proposal and theirs predict a subtle but interesting contrast, depending on whether only the numeral or the whole DP is focused (see also Fox 2007b):

(43) a. What books does Jack have to read in order to pass the exam? Jack only has to read [more than three novels by Balzac $]_{\mathrm{F}}$.

b. \#... He must actually read the first four novels that Balzac wrote

c. \#... But he also has to read a novel by Flaubert

(44) a. Jack only has to read more than [three $]_{\mathrm{F}}$ novels by Balzac.

b. ... He must actually read the first four novels that Balzac wrote.

c. ... But he also has to read a novel by Flaubert. 


\subsection{Modified Numerals under a Possibility Modal}

Consider now:

a. What novels is Jack allowed to read ?

b. Jack is allowed to read [more than three novels by Balzac $]_{F}$

Under its higher-order reading, (45a) denotes the set of all true propositions of the form Jack is allowed to read $G$, with $\mathrm{G}$ a quantifier over novels. It turns out that in no world can (45b) be the complete answer to (45a) under the higher-order reading. For suppose that $(45 \mathrm{~b})$ is true in $w$ : this means that there is a world w' that is permissible from the point view of w such that Jack reads more than three novels by Balzac in w'. Let X be the plurality made up of all novels that Jack reads in w' (we know that X contains more than three novels by Balzac). Since Jack reads X in w' and w' is permissible in w, it is true in w that Jack is allowed to read X. But the proposition that Jack is allowed to read X therefore belongs to the denotation of (45a) in w, and is strictly stronger than (45b). Hence (45b) cannot the complete answer. It follows that applying $O p_{Q}$ to (45b) as whole results in the contradictory proposition. Therefore the only option left if we want to strengthen the meaning of (45b) is to use the syntactic trick described in section 3. 3, which yields the following logical form:

[More than three novels by Balzac] $\left[\lambda \mathrm{x} . \mathrm{Op}_{(45) \mathrm{a}}(\mathrm{Jack}\right.$ is allowed to read $\mathrm{x}]$

This corresponds to the following reading:

(47) There is a group of books consisting of more than three novels by Balzac such that we are allowed to read this group of books and we are not allowed to read any other book.

So there is no way to derive the unwanted implicature (i.e., that Jack is not allowed to read more than four books) ${ }^{19}$. More generally, modified numerals within a focused DP are predicted to give rise to an implicature when the DP is embedded under a necessity modal, but not when it is embedded under a possibility modal or not embedded at all.

\footnotetext{
${ }^{19}$ Clearly, we do not derive at this point the following reading, which is probably the most natural one for (45): 'Jack is allowed to read any group of books consisting of more than two novels by Balzac, and he is not allowed to read books that are not by Balzac'. This is an instance of the so-called free-choice interpretation of indefinites within the scope of possibility modals. The derivation of free-choice effects goes beyond the scope of this paper.
} 


\section{Conclusion}

In this paper, I showed that the interpretation of modified numerals within focused DPs follows from the following assumptions:

- Implicatures are derived by means of an exhaustivity operator that can be inserted locally, within the scope of some other expressions.

- This operator takes two arguments, a proposition S, and a question Q, and returns the proposition that states that $\mathrm{S}$ is the complete answer to $\mathrm{Q}$. The more sophisticated type of exhaustivity operator assumed by G\&S (1984), van Rooij \& Schulz (2004, 2006), Spector (2003, 2006) and Fox (2007a) can be dispensed with thanks to the first assumption.

- Wh-questions are ambiguous between the interpretation assumed by Karttunen (1977) and a 'higher-order' interpretation;

The exhaustivity operator could be defined as well as taking a proposition $\mathrm{S}$ and a set of propositions $\operatorname{Alt}(\mathrm{S})$ (a 'focus value' instead of a question) as its arguments, provided the focus value of an increasing GQ is defined as the set of all increasing GQs over a contextually determined set X (an assumption that receives support from the existence of the higher-order interpretation of wh-questions).

One last remark: my account is clearly a particular instance of a more general type of account described in Fox (2007b). Namely, the fact that certain expressions have a large set of alternatives is used to predict the absence of any implicature in non-embedded contexts or within the scope of possibility modals, and the presence of implicatures within the scope of necessity modals.

\section{References}

Beck, Sigrid and Holtze Rullman: 1999, 'A flexible approach to exhaustivity in questions', Natural Language Semantics 7, 249-298.

Chierchia, Gennaro: 1991, 'Functional WH and weak crossover', in Dawn Bates (ed.), Proceedings of the Tenth West Coast Conference on Formal Linguistics, CSLI, Stanford.

Engdahl, Elisabeth: 1986, Constituent questions, Kluwer, Dordrecht.

Fox, Danny, and Martin Hackl: 2006, 'The Universal Density of Measurement', Linguistics and Philosophy 29, 537-586.

Fox, Danny: 1999, 'Reconstruction, binding theory, and the interpretation of chains', Linguistic Inquiry 30, 157-196.

Fox, Danny: 2007a, 'Free Choice Disjunction and the Theory of Scalar Implicatures' in U. Sauerland and P. Stateva (eds.) Presupposition and Implicature in Compositional Semantics, Palgrave Macmillan, New York. 
Fox, Danny: 2007b, 'Too many alternatives: density, symmetry and other predicaments', paper presented at SALT 17.

Ginzburg, Jonathan: 1995a. 'Resolving questions I'. Linguistics and Philosophy 18, 459-527.

Ginzburg, Jonathan: 1995b. 'Resolving questions II'. Linguistics and Philosophy 18, 567-609.

Groenendijk, Jeroen. and Martin Stokhof: 1984, Studies on the semantics of questions and the pragmatics of answers, Doctoral Dissertation, University of Amsterdam.

Karttunen, Lauri: 1977, 'Syntax and semantics of questions' Linguistics and Philosophy 1, 3-44.

Keshet, Ezra: 2006, 'Scalar Implicatures with Alternative Semantics', Ms., MIT.

Kratzer, Angelika: 2005, 'LSA class notes'

Krifka, Manfred: 1993, 'Focus, presupposition and dynamic interpretation', in Bimbò \& Máté (eds.) Proceedings of the Fourth symposium on Logic and Language, Aron Pubslishers, Budapest.

Kucerova, Ivona: 2007, Notes on Czech Split Constructions, Ms., MIT.

Rooij, Robert van: 2003, 'Questioning to resolve decision problems', Linguistics and Philosophy 26, 727-763.

Rooij, Robert van \& Katrin Schulz: 2004, 'Exhaustive interpretation of complex sentences', Journal of Logic, Language, and Information 13, 491-519

Rooij, Robert van \& Katrin Schulz: 2006, 'Pramatic Meaning and NonMonotonic Reasoning: the case of Exhaustive Interpretation', Linguistic and Philosophy 29, 205-250.

Russell, Benjamin: 2006, 'Against Grammatical Computation of Scalar Implicatures', Journal of Semantics 23, 361 - 382.

Sharvit, Yael: 1999, 'Functional relative clauses', Linguistics and Philosophy 22, 447-478.

Sharvit, Yael: 2002, 'Embedded questions and 'de dicto' readings', Natural Language Semantics 10, 97-123.

Spector, Benjamin: 2003, 'Scalar Implicatures: Exhaustivity and Gricean Resaoning', in B. ten Cate (ed.) Proceedings of the ESSLLI'03 student session, Vienna.

Spector, Benjamin : 2006, Aspects de la pragmatique des opérateurs logiques, Doctoral Dissertation, Université Paris 7.

Spector, Benjamin: 2007, 'Scalar Implicatures: Exhaustivity and Gricean Resaoning', in M. Aloni et al (eds.) Questions in Dynamic Semantics, Current Research at the Semantics/Pragmatics Interface, Elsevier

Spector, Benjamin: 2007 'An unnoticed reading for wh-questions: elided answers and weak-island effects', Ms., Harvard University.

Szabolcsi, Anna: 1997, 'Background notions in lattice theory and generalized quantifiers' in A. Szabolcsi (ed.) Ways of Scope Taking, Kluwer. 